\title{
The COVID PANDEMIC: RESPONSE OF THE RAJI Revitalization Programmes
}

\author{
Kavita Rastogi \\ University of Lucknow
}

\begin{abstract}
Raji is a little known tribal community that resides in twelve geographically scattered hamlets in the state of Uttarakhand, India. According to 2011 Census, their total population is 732. Their language belongs to Tibeto-Burman family. Since, last twenty years or so the author has been working with this group and trying to document, preserve and revitalize their language and culture. Language revitalization requires tackling problems on many fronts and its different approaches depend upon the unique local conditions of the speech community. The author is trying to develop a new revitalization model called 'South Asian Model of Language Revitalization'. This paper discusses the Response of the Raji Revitalization Program towards the present pandemic and sheds light upon the effect of the Covid-19 pandemic on the Raji community and the status of their language.
\end{abstract}

Key words: Raji Community, Language Documentation and Revitalization

\section{INTRODUCTION}

Raji /Banraji/ Banmanus / Rawat /Rajbaar is one of the last hunter-gatherers of a little - known primitive tribe of India which was brought into light for the first time in 1823 . The word ' $b^{\text {h}}$ ulla' was used earlier by them for themselves. By nature, they are shy, aloof, strong-headed, and do not want to interact with other communities. Due to these characteristics, Mazumdar, way back in 1944, has called them 'invisible traders' . During fieldwork, I noticed that they still prefer to sit in the dark, invisible corners of the dhabas \& shops of nearby markets. Due to previous experiences, they have become suspicious of outsiders and do not easily trust others and as a result data collection has been a herculean task. Previously langur and porcupine hunting were their favourite occupation. Apart from this, they used to make wooden pots and vessels. But in the post-independence era, they were compelled to lead a settled life. As a result, to earn their bread and butter they shifted to agriculture, fish rearing, beekeeping, and often work as daily wage laborers. At present, they are geographically scattered and live in eleven small hamlets which fall in two districts- Pithoragarh and Champawat in the state of Uttarakhand, India. All their hamlets are 10 to 20 kilometres away from main markets and situated at an altitude of 2000$5000 \mathrm{ft}$. in dense forest. So, to work as laborers, to fulfil their daily needs and for education, they have to travel a lot. Their newly formed hamlets Khirdwari and Chakarpur are around $50 \mathrm{~km}$ away from Pithoragarh and are situated in the low lying (tarai) area. In 1982 around twenty Raji families migrated here in search of food and work. This second migration has made a deep impact on their language and culture. The earlier migration was probably in the eighteenth century when they came to India from Nepal through a jungle route and started to settle in the early 19th century in caves. According to the 2011 Census, their total population is around 732.

\section{A. Raji Language \& Communicative Patterns}

The name of their language is also Raji (ISO 639-3 code jnl) (2015). Grierson (1909), in his book 'Linguistic Survey of India,' had named this language as 'janggali'; and due to its geographical affinity placed it in the Tibeto-Burman family. Chatterjee (1926) also supported Grierson's claim. On the other hand, some linguists like Shobha. R. Sharma (1987)and D.D. Sharma (1994) have suggested that the linguistic components of Raji language were paleo-linguistic relics of some of the Munda dialects, which, in the ancient past were spoken in the Himalayan region. In my previous works (Rastogi: 2002; 2012) I have tried to establish that though this indigenous language belongs to the Central Himalayish branch of Tibeto-Burman family yet long contact with Indo-Aryan languages like Kumauni and Hindi (henceforth K/Hindi) has not only affected its vocabulary but also its grammar.

The entire community is bilingual, everyone can speak Raji and $\mathrm{K} /$ Hindi though the competency may vary depending on their age, educational level and contact situations. Some of

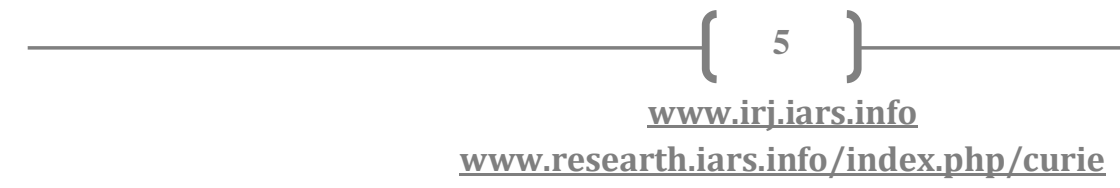




\section{Yinternational Research Journa!}

p-ISSN 2202-2821 e-ISSN 1839-6518 (Australian ISSN Agency)

them are trilingual and can also speak Nepali fluently. Raji is the preferred language for home and intergenerational transfer is playing an important role in the maintenance of the language. However, in 2019 during a workshop, some mothers complained to us that though their elder children speak Raji at home the younger ones (mostly boys) no longer want to speak Raji. We know that borrowing generally does not create a threat for the existence of any language in the situation when the borrowed term represents a different worldview but when the community starts replacing original words the situation becomes critical for the identity of a language. I have noticed this phenomenon since long that instead of using original Raji word for many concepts the younger generation speak $\mathrm{K} / \mathrm{H}$ words and over time the younger generation has lost these native words. For example, in 2001 during data collection some informants used the word 'garphuliaya' for earthworm whereas some called it 'kechuwa' (Hindi). In 2017 when I asked the school children to show an earthworm all of them used the Hindi word. Not a single child was aware of the original Raji word. Thus, gradually they are losing the native words in Raji and replacing them with $\mathrm{K} / \mathrm{H}$.

\section{B. Current State of Raji}

The author has been working with this group for the last twenty years and based on collected data and information it can be said that Raji is on the brink of decay as shrinking domains of use may relegate it soon also from the home environment. So many K/H words have been assimilated and several borrowed terms have been incorporated in the language that the language is swiftly losing its identity. As a result, peeling out the layers of various levels of language structure and commenting on its genetic relationship has become difficult. It is facing the problems that any endangered language faces: a very low socio-economic status, minuscule number of speakers, code-reduction, diminishing language attitude, etc. But as usual, the causal factors of language endangerment are mostly non-linguistic, and largely, sociopolitico-economic. Let us visualize their situation-when a historically nomadic forest-dwelling people are forced (by misplaced saviour complex of the local or national government) to assimilate in the mainstream- their economic dependence on the neighbouring community increases as traditional methods of survival increasingly become redundant. The Rajis went through this exact tangent of events. Governmental development programmes have been either poorly envisioned, executed or both. The dwindling population, dismal life expectancy, and apathy by political parties to take up their cause are other problems, directly and indirectly, affecting the language.
Vol. 11 No. 012021 82801101202102

\section{Revitalization Programmes}

When linguists along with speakers try to reverse the process of language shift and make an attempt to revive the slipping language, it is called language revitalization. In 2002 after assessing the situation of Raji community I have chalked out the revitalization programmes for the community. At that time, I took up four objectives-

- Documentation and preparation of grammar

- Orthography development

- $\quad$ Preparation of Dictionary

- Creation of a Community-learning Centre

Most of the academia think if the community is not interested in the revival of their language and culture for whatever reason may be, a linguist must leave them to their situation and should wait till the time the community is ready for a revitalization programme or come forward and ask the researcher to help them. I have a different opinion, especially in the South Asian context. Here most of the tribal communities are socially, economically, educationally, and politically so suppressed and dominated by others that often they are not in a position to make decisions for themselves and mostly the state decides for them and instead of preserving and promoting their language and culture, they emphasize assimilation. In such a situation a researcher, who can be a linguist, an anthropologist, or an environmentalist doubles up as a social worker and tries to motivate the community to do the needful.

During all these years I have tried to do the same with the Raji community, often motivating them and sometimes compelling them to come forward. It is a known fact that the resources developed by documentation are often for the academic circle unless the linguist casts them in an orthography. After developing an orthography with the participation of the community, in 2009 the first written record of this endangered language in the form of a primer was published. With their help and cooperation, I collected data and Raji grammar was published in 2012 with financial support from CIIL, Mysore. A multilingual, multiscriptal pictorial Raji dictionary was also published. So apart from the community learning centre, all the goals have been achieved.

In 2017 we conducted a field trip to assess the results of the revitalization programs. The situation was quite disappointing, but we did observe certain good signs. We noticed that things have changed. The Rajis are regularly visiting markets and freely interacting with outsiders. In earlier times Raji was

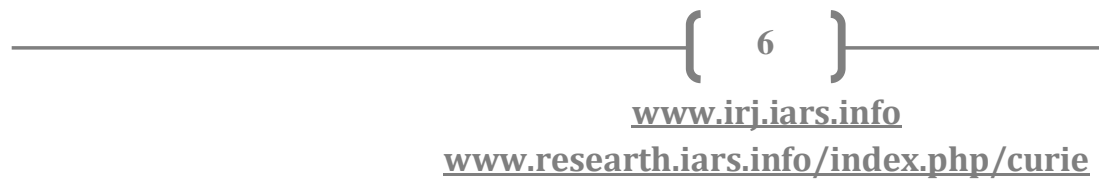




\section{Yinternational Research Journal}

p-ISSN 2202-2821 e-ISSN 1839-6518 (Australian ISSN Agency)

spoken exclusively in the private and intracommunity domain now adults are freely using it in front of Kumauni people (public domain). They do not feel shy or feel any kind of embarrassment about using their language. In fact, some local shopkeepers have learned their language. We tried to look critically at the programs to determine what had been gained and what sort of problems it was facing. We created activities to judge the linguistic attitude of the children, to check their Raji writing skills, and to measure their competence in Raji vocabulary. So, after much brainstorming, we planned some activities to help in empowering the community. We shifted our focus from the preservation of language to the preservation of their cultural heritage and to make them selfreliant and to develop a sense of prestige and dignity in the community. As a result, we added six new objectives in our Revitalization Programs-

- $\quad$ Script re-introduction workshops

- Jewellery making workshops

- Bowl carving workshops

- Creation of new narratives

- Translation of existing content

- Developing language resources

The team visited the community in October 2019 and conducted a few workshops and another visit to the area was scheduled in January. The aim was to conduct a wooden bowl making workshop but this did not materialise due to bad weather conditions. We therefore rescheduled the workshop to March 2020.

\section{The COVID -19 Pandemic}

The Covid-19 Pandemic forced us to further postpone our workshop. During the first lockdown we were getting news about the spread of COVID-19 and as the team leader, I was devastated by the gravity of the situation. As I had a long relationship with the community and was aware of their socioeconomic condition, their hygiene level, and the medical facilities available in the area I was worried and wanted to convey Covid-19 related information to the community. I knew that I had to act fast. As has been mentioned earlier that Raji is a geographically scattered community, all the Raji hamlets are quite far from the main roads and mostly situated in jungles. Due to the lockdown, it was neither possible for us nor for any local NGO to communicate with them physically. Though the mobile network is available in some hamlets only two percent of the Raji population own a mobile. Keeping all these hurdles in mind I planned to create a written information
Vol. 11 No. 012021

82801101202102

flyer in their mother tongue and drafted a flyer in Hindi and then translated it in the Raji language. Once it was completed, I tried hard to contact some community members. I needed someone who could read and understand it. The person should be a mother tongue speaker who still uses Raji language in different domains. He/she should have a smartphone or have access to a smartphone. Helshe must be capable of doing the corrections and should be responsible enough to send it back to us. And most importantly he/she should take the responsibility to circulate the information flyer. While making a draft of the Hindi flyer the following points were given preference-

- Brevity

- Inclusion of relevant information

- Authentic sources

- Easily comprehensible

Bearing in mind these four points an information flyer was first prepared in Hindi. It was clear that the flyer should be small i.e. one page only, so that circulation would be easy but it had to contain all the relevant information. Its language must be clear and coherent. It is a proven fact that pictures make any information more effective and interesting, so a few pictures were selected to convey the information. Instead of taking some random visuals conveying a similar meaning, a government website was consulted, and its name was mentioned in the flyer.

\section{A. Raji flyer \& its cross-checking}

After working with the community for twenty years documenting their language and writing grammar for their mother tongue, I was confident that I could translate the flyer in Raji. There are minor variations between the Hindi and Raji flyers due to the structural differences between both languages. Then came the cross-checking stage and after several attempts luckily, I could contact Sri Gagan Singh Rajbaar. He is an ex - MLA (Member of Legislative Assembly) who lives in Pithoragarh, and he helped us in cross-checking the flyer. His daughter, Jigyasa, a class 7 th student helped in formatting the material and sending it via WhatsApp. As I am not convinced with this translation I am still trying to contact and discuss this with other members of the Raji community. However, since this was provided by a native speaker, we published it and requested him to circulate it. He assured us that he would also print the flyer and send someone to distribute it.

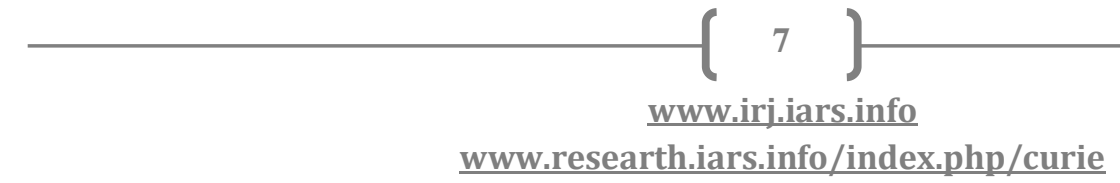




\section{Conclusion}

- This step has fulfilled the linguistic right of a community to get information in their native language.

- The community has some more written linguistic resources in their native language.

- The comparison of the translation created by the author and by the native speaker (who does not use the language in different domains, his children do not speak Raji, he no more resides in the Raji hamlet, and has married a non-Raji) will provide data for further study.

- $\quad$ Based on the feedback received from a community member named Rajini, I am happy to share that all of them are aware of the Pandemic and about the precautions they must take.

- None of the community members is affected by the disease. It seems that timely intervention has helped them.

We have also prepared Covid-19 information flyers in 98 Indian languages. We have tried to address the issue of the availability of COVID-19 awareness literature in the endangered languages in India. Instead of being frightened, and disappointed, we preferred to find ways for our survival and worked for the communities and society at large.

\section{V.REFERENCES}

[1]. Atkinson, Edwin. Thomas. The Himalayan districts of the North West provinces of India. vol II, 18821886, [Reprint: New Delhi, Cosmo Publication, 1973

[2]. Chatterjee, S. K. The Origin and Development of Bengali Language. London. 1926.

[3]. Grierson G. A. Linguistic Survey of India, Vol iii, parts 1,2,3‘Tibeto-Burman Family’. 1909 Calcutta: Govt of India, Central Publication Branch, Motilal Banarsi Das, Varanasi.

[4]. Lewis M. Paul, Gary F. Simons and Charles D. Fennig (eds.). Ethnologue Languages of the World, Eighteenth edition. Dallas, Texas: SIL International. Online version http://www.ethnologue.com. 2015

[5]. Rastogi, K. Raji: Language of a Vanishing Himalayan Tribe, Linguistics of Tibeto-Burman Area, Berkeley Area, Berkeley, USA pp 155-167, Vol, 25.2. Fall 2002.

[6]. Rastogi, Kavita. A descriptive grammar of Raji. New Delhi: Aviram Prakashan. 2012
[7]. Sharma, D. D. A Comparative Grammar of TibetoBurman Languages of Himachal Pradesh and Uttarakhand. Studies in TB languages IV. New Delhi Mittal Publication. 1994

[8]. Sharma, S. R. Madhya Himalaya ki Raji Boli, PahaaR-2 pp 145-156. 1987

[9]. Traill, G. W. Report on Kumaon. Asiatic Researchers: Comprising History and Antiquities, the Arts, Sciences and Literature of Asia.16:150. 1823

[10]. UNESCO field bulletin. Education in Multilingual World. Parid

[11]. Wurm S. A. 1998 Methods of Language Maintenance and Revival, with selected cases of language endangerment in the world. Studies in Endangered Languages (ICHEL Linguistic Studies 1) ed. by K. Matsumura, 191- 211.Tokyo: Hituzi Syobo. 2003

\section{Endnotes}

${ }^{1}$ Department of Linguistics, University of Lucknow, India, krastogi1960@gmail.com

${ }^{1}$ The author has noticed that they have started using this term for themselves recently say around from 2007 -2008. This term is also used by a group of speakers from Nepal.

${ }^{1}$ The Government of India identified them as a scheduled tribe in June 1967; and as a primitive tribe in 1975, due to their socio-economic backwardness.

${ }^{1}$ G.W. Traill was the commissioner of Kumaon during the British period, who for the first time had mentioned Banrajis in his statistical account of Kumaon, pp 19-57. As quoted by Atkinson E.T. (1882:365).

1 "Their trade is carried on with known and trusted agents with whom they do not have any direct or personal contact. They come with their product at midnight and place them in the courtyard of the agents and also keep some symbols by which the latter knows what they want in exchange. Next night when all are asleep, they stealthily enter the courtyard of the agents and take what they get in exchange. They are locally known as invisible traders." p.67.

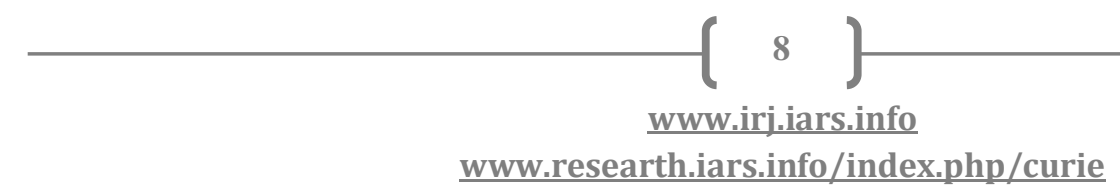




\section{Manuscript Processing Footprints}

\section{A. Journal Volume/Issue Details}

This manuscript it published in Vol. 11 No. 012021 issue of IARS' International Research Journal (I'IRJ).

This is a Peer Reviewed (Refereed) International Journal archived with National Library of Australia.

The mentioned Volume/Issue is a special issue of the journal dedicated to Covid19 Pandemic Conditions across globe.

\section{B. Citation}

Rastogi, Kavita, (2021) “The COVID Pandemic: Response of the Raji Revitalization Programmes”, IARS' International Research Journal.

Vic. Australia, 11(1). Available at: https://researth.iars.info/index.php/curie

\section{Author Declaration}

- The submission has not been previously published, nor is it before another journal for consideration (or an explanation has been provided in Comments to the Editor).

- The submission file is in OpenOffice, Microsoft Word, or RTF document file format.

- Where available, URLs for the references have been provided.

- The text is single-spaced; uses a 12-point font; employs italics, rather than underlining (except with URL addresses); and all illustrations, figures, and tables are placed within the text at the appropriate points, rather than at the end.

- The text adheres to the stylistic and bibliographic requirements outlined in the Author Guidelines.

- All Terms and Conditions about submission and publishing with IARS' International Research Journal on its official site and other sources have been gone through, understood, and accepted.

- With submission, this is declared that the submitter has all rights of the content, and to submit it. Also the submitter affirms that the rights of the submitted content are hereby transferred to IARS' international Research Journal and its parent company/publisher, without objections or conditions.

\section{Last Plagiarism Report}

Settings : similarity of 09 words in a row considered plagiarized.

Originality Assessment

\section{Overall Similarity: $1 \%$}

Date: Dec 20, 2020

Statistics: 16 words Plagiarized / 2883 Total words

Remarks: Low similarity detected, check your supervisor if changes are required.

Sources

http://sealang.net/sala/archives/pdf4/rastogi2002raji.pdf

1

\section{E. Processing Track}

\begin{tabular}{|l|l|}
\hline Date of Submission: & 08 November 2020 \\
\hline Date of Referee/Review - 1: & 21 November 2020 \\
\hline Date of Referee/Review - 2: & 29 November 2020 \\
\hline Date of Additional Review: & NA \\
\hline Date of Acceptance: & 23 December 2020 \\
\hline Date of Publishing: & 08 February 2021 \\
\hline
\end{tabular}

